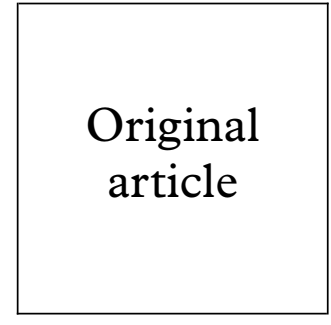

\title{
Racial origin, sexual behaviour, and genital infection among heterosexual men attending a genitourinary medicine clinic in London (1993-4)
}

\author{
B A Evans, R A Bond, K D MacRae
}

Objectives: To compare variables of sexual behaviour and incidence of genital infections among heterosexual men of different racial origins.

Design: A prospective cross sectional study of sexual behaviour reported by a standardised self administered questionnaire in new patients who presented for screening and diagnosis.

Setting: A genitourinary medicine clinic in west London.

Subjects: 1212 consecutive heterosexual men newly attending in 1993-4.

Main outcome measures: Variables relating to sociodemographic status, sexual behaviour, condom use, sexually transmitted diseases, and other genital infections stratified by racial origin. Results: There were 941 evaluable heterosexual men of whom the majority were white $(79 \%)$ and $17 \%$ were black. The black men comprised more teenagers $(11 \%$ cf $2 \% ; p<0.00001)$, were more likely to be unemployed ( $26 \%$ cf $12 \%$; $<<0.0001)$, to have commenced intercourse much earlier $(45 \%$ cf $22 \%$ before aged 16: $\mathrm{p}<0.0001)$, and to have had intercourse with an African woman $(14 \%$ cf $6 \% ; \mathrm{p}<0.001)$. Both fellatio $(64 \% \mathrm{cf} 96 \% ; \mathrm{p}<0.00001)$ and cunnilingus $(40 \% \mathrm{cf}$ $92 \% ; \mathrm{p}<0.00001)$ were practised less frequently by the black men and so too was anal intercourse $(11 \%$ cf $27 \%$; p $<0.0001)$. Similar proportions from both groups were non-smokers $(53 \%$ cf $57 \%)$, but a significantly higher proportion of the black men did not drink alcohol $(13 \%$ cf $5 \%$; $\mathrm{p}<0.001)$. Gonorrhoea ( $15 \%$ cf $1 \%$; $\mathrm{p}<0.00001)$, chlamydial infection $(17 \%$ cf $8 \% ; \mathrm{p}<0.001)$, and non-gonococcal urethritis ( $37 \%$ cf $24 \%$; $=0.001$ ) were diagnosed more frequently in the black men. These findings remained significant after logistic regression and are therefore independently associated with black race. However, there was no significant difference in numbers of sexual partners in the preceding year (median 2), nor in condom use with regular and non-regular partners. The Asian men had commenced intercourse later (mean 19.1 years) than both the black men (mean 15.9 years) and the white men (mean 17.3 years).

Conclusions: Compared with white men, black men attending a genitourinary medicine clinic were much more likely to be unemployed, to have commenced intercourse earlier and to have urethral infection. They were much less likely to practise fellatio, cunnilingus, or anal intercourse. However, there was no difference between the two racial groups in respect of numbers of sexual partners and condom use.

(Sex Transm Inf 1998;74:40-44)

Keywords: race; sexual behaviour; genital infection; heterosexual men; genitourinary medicine clinic; London

\section{Introduction}

Racial differences in age at first heterosexual intercourse in Britain have been documented by the National Study of Sexual Attitudes of Lifestyles (NATSSAL): black men reported intercourse earlier than white men and Asian women reported intercourse later than white women. ${ }^{1}$ This has obvious and important implications for sexual health education and risk of acquiring sexually transmitted infections (STIs). Recent studies from the United States have looked at similar aspects of sexual health in very different demographic settings. ${ }^{2}{ }^{3}$ In this study, we examined men attending for investigation of possible sexually acquired infection using a sexual behaviour questionnaire similar to that described previously in comparable studies of women. ${ }^{4-6}$

\section{Methods}

Sociodemographic data, including racial origin, were self recorded on a standard registration form and a self administered questionnaire was given to newly attending post- pubertal male patients. The first half of the questionnaire was concerned with testing for HIV infection and the risks to which the patient may have been exposed. Questions on sexual behaviour were identical to those used in previous studies on female patients in respect of age at first vaginal intercourse, numbers of sexual partners in the previous year and in total, frequency of vaginal intercourse, oral intercourse, anal intercourse, use of condoms with regular and non-regular partners, and cigarette smoking. The question on menarche was removed and questions on sexuality, oro-vulval contact (cunnilingus), and frequency of alcohol consumption were added. As in previous studies, only those patients who fully completed the questionnaire were entered into the study as a measure of subject commitment and to ensure conformity between responses. Patients who declined examination and screening for STIs were also excluded, so too were men whose English was inadequate for comprehension of the study. 
All men had a full clinical history taken and underwent physical examination for genital disease. Routine screening tests for urethral infection included culture for gonorrhoea (New York City medium) and enzyme immunoassay (Microtrak 2, Syva Diagnostics) for chlamydial detection. Cultures for yeast infection (Sabouraud's medium) and for herpes simplex virus (cell culture) were undertaken where indicated. Serological tests for syphilis were the VDRL and TPHA, plus FTA ABS if either proved positive. Testing for HIV infection required informed consent. Routine testing for hepatitis B infection was carried out only on men who reported risk behaviour or who came from high prevalence areas.

Data analysis employed sPss- $x$ software on a Sun $4 / 670$ computer and STATA 4.0 on a microcomputer. $\chi^{2}$ tests for homogeneity or trend were used to measure significance, incorporating Yates's correction when appropriate. Multivariate analysis by logistic regression was used to adjust for differences in age and socioeconomic class between the white group and the black. The STATA program gives $\mathrm{p}$ values to three decimal places.

\section{Results}

Between September 1993 and September 1994, 1586 consecutive newly attending male patients were given a questionnaire on heterosexual and related behaviour. Of these, 1212 $(81.3 \%)$ assessed themselves as heterosexual, $44(3.0 \%)$ as bisexual, and $234(15.7 \%)$ as homosexual. Ninety six $(6.1 \%)$ who did not record their sexuality were excluded from the study. Of the 1212 heterosexual men, 126 (10.4\%) did not complete the sexual behaviour questionnaire in full, eight $(0.7 \%)$ did not conform to the protocol for admission, and five $(0.4 \%)$ refused. One hundred and sixteen heterosexual men $(9.6 \%)$ attended for HIV testing only and declined full clinical examination and screening for genital infection. A further 16 $(1.3 \%)$ were excluded because their racial origin was unrecorded.

Of the final 941 men, 748 were white $(79.5 \%): 620$ of the white men $(82.9 \%)$ were white European, 65 (8.7\%) were white Australian, $22(2.9 \%)$ were white American, 21 $(2.8 \%)$ were white Middle Eastern and 17 $(2.3 \%)$ were white African. A total of 156 men $(16.6 \%)$ were black: of the black men, 97 (62.2\%) were black European, 29 (18.6\%) were black Caribbean, 27 (17.3\%) were black African, and three $(1.9 \%)$ were black American. Twenty five men were Asian $(2.7 \%)$, seven were Chinese $(0.7 \%)$, and five were unclassifiable $(0.5 \%)$. Comprehensive analysis has been confined to those men who classified themselves as either white or black, but selected data from Asian men have also been included.

SOCIODEMOGRAPHIC VARIABLES

The median age of the black men (27 years) was 1 year younger than the white men, with a significantly higher proportion of teenagers $(\mathrm{p}<0.00001)$ (table 1). Mean ages were 29.1 years and 30.9 years respectively. Division by socioeconomic class showed a higher proportion of professional men in the white group $(p<0.00001)$ and higher proportions of blue collar workers $(p=0.0003)$ and of unemployed men $(p=0.00004)$ in the black group.

SEXUAL BEHAVIOUR

Our findings accord with those of others in respect of age at first intercourse (coitarche) with highly significant differences: $44.9 \%$ of the black men reported intercourse before the age of 16 compared with $21.8 \%$ of the white men $(\mathrm{p}<0.0001)$. Mean age at coitarche was 17.3 years for white men (median 17 years) and 15.9 years (median 16 years) for black men (table 2).

On the other hand, the numbers of sexual partners reported in the past year (median 2) showed no significant difference. This also applied to the frequency of vaginal intercourse.

Oral intercourse (both fellatio and cunnilingus) was practised much more frequently by the white men than the black men $(p<0.00001)$. This also applied to anal intercourse with penile insertion alone $(p=0.00004)$ and with ejaculation $(\mathrm{p}=0.008)$. Condom use did not differ significantly with regular and non-regular partners, nor was there any difference in the proportion of men reporting non-regular partners.

\section{CIGARETTE SMOKING AND ALCOHOL}

\section{CONSUMPTION}

There was no difference in the proportion of men in both groups who smoked, but of those who did smoke, the white men smoked more heavily: $23.7 \%$ of white men smoked more than 10 cigarettes a day, but only $9.6 \%$ of black men did so $(\mathrm{p}<0.0002)$. Alcohol consumption showed more marked differences: only $5.1 \%$ of the white men reported no alcohol consumption compared with $12.8 \%$ of the black $(\mathrm{p}<0.0007)$ and a much higher proportion of the white men drank more frequently, 53.3\% reporting alcohol consumption more often than weekly against $18.6 \%$ of the black men $(\mathrm{p}<0.00001)$.

GENITAL INFECTION

There were striking differences in the incidence of four genital infections between white men and black (table 3 ). The black men were much more likely to suffer from gonorrhoea $(p<0.00001)$, chlamydial infection $(p=0.0009)$, or to have non-gonococcal urethritis $(p=0.001)$. Conversely, genital warts were found more frequently in white men $(\mathrm{p}=0.003)$.

SYPHILIS

Nine men had positive serological tests for treponemal infection. All were non-United Kingdom born: there were eight black men and one white man who gave a history of recent treatment for syphilis in Australia. Of the black men, only one had a positive VDRL (in neat serum); four gave a past history of treatment for syphilis or yaws and four were diagnosed and treated for late latent treponemal infection. There was no case of early infectious syphilis. 
HIV TESTING AND INFECTION

There was no difference in the proportions who consented to HIV testing, nor in risks involving injecting drug use or homosexual intercourse. However, significantly more black men reported intercourse with African women $(\mathrm{p}<0.001)$. Two out of 271 men $(0.7 \%)$ tested positive for HIV infection. Both attended for HIV testing and classified themselves as white English. One, aged 46 years, worked in Egypt and had been married to an Egyptian wife for four years; he denied extramarital intercourse or any other risk behaviour and his wife tested
HIV negative elsewhere. His CD4 count was $290 \times 10^{6} / 1(9 \%)$ and he also had chlamydial infection of the urethra on presentation and again 4 months later. The other man was aged 35 years and single; he gave a history of intravenous drug use with needle sharing 10 years previously and of sexual intercourse on several occasions abroad with a Cambodian woman, 6-8 weeks previously, when on one occasion the condom broke. He denied any other risk behaviour. However, his HIV tests showed recent seroconversion and he also tested positive for hepatitis C.

Table 1 Racial origin, sociodemography, and sexual behaviour: men, 1993-4

\begin{tabular}{|c|c|c|c|c|c|}
\hline \multirow[b]{2}{*}{ Variables } & \multicolumn{2}{|l|}{ Racial origin } & \multirow[b]{2}{*}{$\chi^{2}$} & \multirow[b]{2}{*}{ p Value } & \multirow{2}{*}{$\begin{array}{l}\text { Adjusted } p \\
\text { value }\end{array}$} \\
\hline & White $(n=748)$ & Black $(n=156)$ & & & \\
\hline \multicolumn{6}{|l|}{ Age (years): } \\
\hline Under 20 & $17(2.0 \%)$ & $17(10.9 \%)$ & 27.3 & $<0.00001$ & \\
\hline $20-24$ & $168(22.5 \%)$ & $41(26.3 \%)$ & & & \\
\hline $25-29$ & $243(32.5 \%)$ & $31(19.9 \%)$ & $\chi_{\mathrm{T}}^{2}=0.2$ & 0.6 & \\
\hline $30-39$ & $191(25.5 \%)$ & $45(28.8 \%)$ & & & \\
\hline 40 and over & $131(17.5 \%)$ & $22(14.1 \%)$ & & & \\
\hline Marital status: & $\mathrm{n}=744$ & & & & \\
\hline Single & $577(77.6 \%)$ & $127(81.4 \%)$ & 0.9 & 0.3 & 0.5 \\
\hline Married & $99(13.3 \%)$ & $20(12.8 \%)$ & 0.001 & 1.0 & 0.9 \\
\hline Separated/divorced & $65(8.7 \%)$ & $8(5.1 \%)$ & 1.8 & 0.2 & 0.4 \\
\hline Socioeconomic class: & $n=697$ & $n=136$ & & & \\
\hline Professional & $211(30.3 \%)$ & $3(2.2 \%)$ & 45.5 & $<0.00001$ & $<0.001$ \\
\hline White collar & $208(29.8 \%)$ & $33(24.3 \%)$ & 1.5 & 0.2 & $<0.001$ \\
\hline Blue collar & $111(15.9 \%)$ & $38(27.9 \%)$ & 13.0 & 0.0003 & $<0.001$ \\
\hline Unemployed & $83(11.9 \%)$ & $35(25.7 \%)$ & 16.8 & 0.00004 & $<0.001$ \\
\hline Student & $76(10.9 \%)$ & $24(17.6 \%)$ & 4.3 & $<0.04$ & $<0.001$ \\
\hline Smoking (no of cigarettes): & $\mathrm{n}=748$ & $\mathrm{n}=156$ & & & \\
\hline Nil & $423(56.6 \%)$ & $82(52.6 \%)$ & 0.7 & 0.4 & 0.3 \\
\hline $1-10 /$ day & $148(19.8 \%)$ & $59(37.8 \%)$ & 22.8 & $<0.00001$ & $<0.001$ \\
\hline$>10 /$ day & $177(23.7 \%)$ & $15(9.6 \%)$ & 14.4 & $<0.0002$ & $<0.001$ \\
\hline \multicolumn{6}{|l|}{ Alcohol: } \\
\hline Nil & $38(5.1 \%)$ & $20(12.8 \%)$ & 11.6 & $<0.0007$ & $<0.001$ \\
\hline Weekly or less & $311(41.6 \%)$ & $107(68.6 \%)$ & 36.8 & $<0.00001$ & $<0.001$ \\
\hline More than weekly & $399(53.3 \%)$ & $29(18.6 \%)$ & 61.1 & $<0.00001$ & $<0.001$ \\
\hline \multicolumn{6}{|l|}{ Coitarche (years): } \\
\hline $6-15$ & $163(21.8 \%)$ & $70(44.9 \%)$ & & & \\
\hline 16 & $106(14.2 \%)$ & $27(17.3 \%)$ & & & \\
\hline 17 & $150(20.1 \%)$ & $25(16.0 \%)$ & $\chi_{\mathrm{T}}^{2}=49.9$ & $<0.00001$ & $<0.001$ \\
\hline 18 & $129(17.2 \%)$ & $17(10.9 \%)$ & & & \\
\hline $19-30$ & $200(26.7 \%)$ & $17(10.9 \%)$ & & & \\
\hline \multicolumn{6}{|l|}{ Partners in past year: } \\
\hline $0-1$ & $308(41.2 \%)$ & $62(39.7 \%)$ & & & \\
\hline 2 & $194(25.9 \%)$ & $40(25.6 \%)$ & $\chi_{\mathrm{T}}^{2}=0.05$ & 0.8 & 0.7 \\
\hline $3-5$ & $175(23.4 \%)$ & $41(26.3 \%)$ & & & \\
\hline$>5$ & $71(9.5 \%)$ & $13(8.3 \%)$ & & & \\
\hline \multicolumn{6}{|l|}{ Partners in lifetime: } \\
\hline 1 & $17(2.3 \%)$ & $8(5.1 \%)$ & & & \\
\hline $2-5$ & $196(26.2 \%)$ & $29(18.6 \%)$ & & & \\
\hline $6-10$ & $173(23.1 \%)$ & $32(20.5 \%)$ & $\chi_{T}^{2}=0.7$ & 0.4 & 0.5 \\
\hline $11-20$ & $178(23.8 \%)$ & $50(32.1 \%)$ & & & \\
\hline$>20$ & $184(24.9 \%)$ & $37(23.7 \%)$ & & & \\
\hline \multicolumn{6}{|l|}{ Vaginal intercourse: } \\
\hline$<1 /$ week & $202(27.0 \%)$ & $30(19.2 \%)$ & & & \\
\hline $1-3 /$ week & $294(39.3 \%)$ & $72(46.2 \%)$ & $\chi_{\mathrm{T}}^{2}=1.7$ & 0.2 & 0.3 \\
\hline$>3 /$ week & $252(33.7 \%)$ & $54(34.6 \%)$ & & & \\
\hline Oral intercourse: & & & & & \\
\hline Fellatio & & & & & \\
\hline insertion & $715(95.6 \%)$ & $100(64.1 \%)$ & 140.6 & $<0.00001$ & $<0.001$ \\
\hline ejaculation & $497(66.5 \%)$ & $45(28.8 \%)$ & 74.4 & $<0.00001$ & $<0.001$ \\
\hline Cunnilingus & $691(92.4 \%)$ & $63(40.4 \%)$ & 248.4 & $<0.00001$ & $<0.001$ \\
\hline Anal intercourse: & & & & & \\
\hline insertion & $200(26.7 \%)$ & $17(10.9 \%)$ & 16.9 & 0.00004 & 0.002 \\
\hline ejaculation & $104(13.9 \%)$ & $9(5.8 \%)$ & 7.1 & 0.008 & 0.9 \\
\hline Condom use: & & & & & \\
\hline Regular partners & $\mathrm{n}=737$ & $\mathrm{n}=154$ & & & \\
\hline Never & $293(39.8 \%)$ & $68(44.2 \%)$ & & & \\
\hline Occasionally/often & $318(43.1 \%)$ & $66(42.9 \%)$ & $\chi_{\mathrm{T}}^{2}=1.8$ & 0.2 & 0.2 \\
\hline Always & $126(17.1 \%)$ & $20(13.0 \%)$ & & & \\
\hline Non-regular partners & $\mathrm{n}=481(64.3 \%)$ & $\mathrm{n}=107(68.6 \%)$ & 0.9 & 0.4 & 0.4 \\
\hline Never & $64(13.3 \%)$ & $18(16.8 \%)$ & & & \\
\hline Occasionally/often & $238(49.5 \%)$ & $51(47.7 \%)$ & $\chi_{\mathrm{T}}^{2}=0.5$ & 0.5 & 0.3 \\
\hline Always & $179(37.2 \%)$ & $38(35.5 \%)$ & & & \\
\hline Risks for HIV infection: & & & & & \\
\hline Injecting drug user (IDU) & $12 / 737(1.6 \%)$ & $1 / 153(0.7 \%)$ & 0.3 & 0.6 & 0.2 \\
\hline Heterosexual intercourse: & & & & & \\
\hline with IDU & $21 / 730(2.9 \%)$ & $4 / 153(2.6 \%)$ & 0.0 & 1.0 & 0.2 \\
\hline with African & $43 / 734(5.9 \%)$ & $21 / 151(13.9 \%)$ & 10.9 & $<0.001$ & $<0.001$ \\
\hline with others abroad & $113 / 734(15.4 \%)$ & $12 / 151(7.9 \%)$ & 5.1 & 0.02 & 0.01 \\
\hline Homosexual intercourse & $11 / 736(1.5 \%)$ & $1 / 153(0.7 \%)$ & 0.2 & 0.7 & 0.7 \\
\hline
\end{tabular}


Table 2 Racial origin, coitarche, and partners: men, 1993-4

\begin{tabular}{|c|c|c|c|c|c|c|c|c|c|c|}
\hline \multirow[b]{2}{*}{ Racial origin } & \multicolumn{10}{|c|}{ Age at coitarche (years) } \\
\hline & $<13$ & 13 & 14 & 15 & 16 & 17 & 18 & 19 & 20 & $>20$ \\
\hline White ${ }^{\star}+(\mathrm{n}=748)$ & $13(1.7 \%)$ & $21(2.8 \%)$ & $49(6.6 \%)$ & $80(10.7 \%)$ & $106(14.2 \%)$ & $150(20.1 \%)$ & $129(17.2 \%)$ & $84(11.2 \%)$ & $55(7.4 \%)$ & $61(8.2 \%)$ \\
\hline Black ${ }^{\star} \ddagger(n=156)$ & $15(9.6 \%)$ & $5(3.2 \%)$ & $12(7.7 \%)$ & $38(24.4 \%)$ & $27(17.3 \%)$ & $25(16.0 \%)$ & $17(10.9 \%)$ & $8(5.1 \%)$ & $4(2.6 \%)$ & $5(3.1 \%)$ \\
\hline Asiant $\neq(n=25)$ & 0 & 0 & $1(4.0 \%)$ & $3(12.0 \%)$ & $2(8.0 \%)$ & $3(12.0 \%)$ & $5(20.0 \%)$ & $1(4.0 \%)$ & $3(12.0 \%)$ & $7(28.0 \%)$ \\
\hline
\end{tabular}

Sexual partners in past year

\begin{tabular}{|c|c|c|c|c|c|c|c|c|c|c|}
\hline & 0 & 1 & 2 & 3 & 4 & 5 & 6 & 7 & 8 & $>8$ \\
\hline White $†$ & $25(3.3 \%)$ & $283(37.8 \%)$ & $194(25.9 \%)$ & $92(12.3 \%)$ & $53(7.1 \%)$ & $30(4.0 \%)$ & $23(3.1 \%)$ & $7(0.9 \%)$ & $6(0.8 \%)$ & $35(4.7 \%)$ \\
\hline 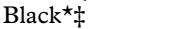 & $6(3.8 \%)$ & $56(35.9 \%)$ & $40(25.6 \%)$ & $21(13.5 \%)$ & $9(5.8 \%)$ & $11(7.1 \%)$ & $4(2.6 \%)$ & $1(0.6 \%)$ & 0 & $8(5.1 \%)$ \\
\hline Asian $† \ddagger$ & $1(4.0 \%)$ & $11(44.0 \%)$ & $4(16.0 \%)$ & $3(12.0 \%)$ & $1(4.0 \%)$ & $1(4.0 \%)$ & $1(4.0 \%)$ & $1(4.0 \%)$ & 0 & $2(8.0 \%)$ \\
\hline & \multicolumn{10}{|c|}{ Total sexual partners } \\
\hline & 1 & 2 & 3 & 4 & 5 & $6-7$ & $8-10$ & $11-20$ & $21-50$ & $>50$ \\
\hline White $\nmid(n=748)$ & $17(2.3 \%)$ & $40(5.3 \%)$ & $64(8.6 \%)$ & $50(6.7 \%)$ & $42(5.6 \%)$ & $72(9.6 \%)$ & $101(13.5 \%)$ & $178(23.8 \%)$ & $133(17.8 \%)$ & $51(6.8 \%)$ \\
\hline Black $^{\star} \ddagger(n=156)$ & $8(5.1 \%)$ & $4(2.6 \%)$ & $9(5.8 \%)$ & $9(5.8 \%)$ & $7(4.5 \%)$ & $13(8.3 \%)$ & $19(12.2 \%)$ & $50(32.1 \%)$ & $31(19.9 \%)$ & $6(3.8 \%)$ \\
\hline \multirow[t]{2}{*}{ Asian $† \ddagger(n=25)$} & $3(12.0 \%)$ & $3(12.0 \%)$ & $4(16.0 \%)$ & $3(12.0 \%)$ & $1(4.0 \%)$ & $1(44.0 \%)$ & $1(4.0 \%)$ & $1(4.0 \%)$ & 0 & $2(8.0 \%)$ \\
\hline & ${ }^{\star} \chi_{\mathrm{T}}^{2}=0.03$ & $\mathrm{p}=0.9$ & $\ddagger \chi_{\mathrm{T}}^{2}=0.2$ & $\mathrm{p}=0.7$ & \multicolumn{2}{|c|}{$+\chi_{\mathrm{T}}^{2}=0.3$} & & & & \\
\hline
\end{tabular}

\section{MULTIVARIATE ANALYSIS}

Only less frequent anal ejaculation and a lower incidence of genital warts were removed by logistic regression as not significantly and independently associated with the men of black racial origin. This is most likely to have resulted from age and socioeconomic class differences.

ASIAN MEN

The 25 Asian men had a mean age of 29.1 years, median 29 years; there were no teenagers and only six (24\%) were under 25 years of age. Nineteen $(76 \%)$ were single and five (20\%) were married. The mean age at coitarche was 19.1 years, much later than the other two racial groups (cf white $\mathrm{p}=0.01$; cf black $\mathrm{p}<0.0001$, table 2). The median number of sexual partners in the previous year was two, the same as the other groups and the median lifetime total was six, less than the other groups (cf white $\mathrm{p}=0.04$; cf black $\mathrm{p}=0.02$ ). Oral intercourse (fellatio) was reported by 20 (80\%), including ejaculation in 17 (68\%). Cunnilingus was also practised by 17 Asian men (68\%). Insertive anal intercourse was reported by six (24\%) with ejaculation by only one $(4 \%)$. With regular partners, condoms were never used by four (16\%) and always used by six (24\%). Among the 14 (56\%) who reported nonregular partners, the figures were one $(7.1 \%)$ and eight $(57.1 \%)$ respectively. Forty per cent of the Asian men reported vaginal intercourse

Table 3 Racial origin and sexually transmitted infections in men, 1993-4

\begin{tabular}{lccccc}
\hline \multicolumn{4}{c}{ Racial origin } & & \\
\cline { 2 - 4 } Genital infections & White $(n=748)$ & $\begin{array}{l}\text { Black } \\
(n=156)\end{array}$ & $\chi^{2}$ & p Value & $\begin{array}{l}\text { Adjusted } p \\
\text { value }\end{array}$ \\
\hline Gonorrhoea & $7(0.9 \%)$ & $24(15.4 \%)$ & 77.1 & $<0.00001$ & $<0.001$ \\
Chlamydial infection & $58(7.8 \%)$ & $26(16.7 \%)$ & 11.1 & 0.0009 & 0.02 \\
Non-gonococcal urethritis & $178(23.8 \%)$ & $57(36.5 \%)$ & 10.2 & 0.001 & 0.008 \\
Candidal balanitis & $39(5.2 \%)$ & $6(3.8 \%)$ & 0.3 & 0.6 & 0.6 \\
Genital herpes & $37(4.9 \%)$ & $5(3.2 \%)$ & 0.5 & 0.5 & 0.6 \\
Genital warts & $105(14.0 \%)$ & $8(5.1 \%)$ & 8.6 & 0.003 & 0.06 \\
NAD & $253(33.8 \%)$ & $39(25.0 \%)$ & 4.2 & 0.04 & 0.03 \\
\hline
\end{tabular}

less than once a week, $56 \%$ did not smoke, and $24 \%$ did not drink alcohol. HIV testing was accepted by $52 \%$. No Asian man had gonorrhoea, but eight $(32 \%)$ had non-gonococcal urethritis (NGU), of whom three showed chlamydial infection. There were four men $(16 \%)$ with genital warts, one $(4 \%)$ with genital herpes, and three (12\%) with candidal balanitis. Four (16\%) had no infection detected and all 10 who were tested for HIV infection were negative.

\section{Discussion}

Our findings show a remarkable similarity to those of O'Donnell et al who studied patients attending a sexually transmitted disease clinic in the South Bronx during 1992. ${ }^{2}$ They found anal sex reported by $11.6 \%$ of 1248 black men, compared with $10.9 \%$ of 156 black men in our study: $52.3 \%$ reported oral sex, compared with our figure of $64.1 \%$. Like us, they compared condom use with steady and non-steady partners. Our figures are given in brackets. In the Bronx, 39.3\% never used condoms with steady partners $(44.2 \%)$ and $10.7 \%$ always did $(13.0 \%)$. With non-steady partners, $16.8 \%$ never used condoms $(16.8 \%)$ and $27.8 \%$ always did $(35.5 \%)$. Condom use in black men in New York is therefore remarkably similar to condom use by black men in London in a similar setting.

In another study, Johnson et al compared black and white college students in the southern United States. ${ }^{3}$ Like us, they found gonorrhoea more frequently in black men with $18 \%$ reporting a past history compared with $8 \%$ of white men, but there was no difference in the incidence of genital warts between the two groups. Reported condom use was also similar with $34 \%$ of black students and $33 \%$ of white students using condoms always and $23 \%$ of black and $27 \%$ of white never using them. Despite this similarity, HIV and syphilis were each reported by $7 \%$ of black students, but not by any white students. 
In our cross sectional study black men comprised $16.6 \%$, which exceeded that in the local community where the 1991 census found that $10.2 \%$ of the male population were black. In the same census, men of Asian origin formed $4.2 \%$ of the local population, but only $2.7 \%$ of our patients were Asian, so our findings for men were similar to those for women where $16.3 \%$ were black and $2.1 \%$ were Asian. ${ }^{6}$

Racial differences were in many respects similar to those that we have reported in women, where we found a significantly greater proportion of black teenagers $(p=0.0004)$ and a significantly lower proportion from the professional socioeconomic class $(\mathrm{p}<0.0002){ }^{6}$ On the other hand there was a significant excess from the blue collar class and from the unemployed among black men, which we did not find among women where the excess was in black students $(p=0.0008)$. The trend analyses showed that both black men and black women tended to be younger at the time they reported first vaginal intercourse. The pattern for oral intercourse was also similar except that fellatio was reported by more men than women generally (white M:F 96\%:88\%; black $\mathrm{M}: \mathrm{F}$ 64\%:51\%). The proportion practising anal intercourse was very similar in both sexes of both groups. We found that black women reported fewer partners (both in the last year and in total) than white women but the two racial groups showed no difference among men. There was also no white/black difference in the frequency of vaginal intercourse reported by both men and women. Approximately two thirds of men (both white and black) reported non-regular partners but only half of white women and one third of black women did so; however, this represents a significant racial difference $(p=0.004)$.

Both racial groups also showed male-female differences: $64 \%$ of white men reported nonregular partners compared with $48 \%$ of white women $(\mathrm{p}<0.00001)$; the figures from the black group were $69 \%$ and $35 \%$ respectively $(p<0.00001)$. The same pattern of behaviour was found with numbers of sexual partners both in the past year and in total-for instance, more than one partner in the past year was reported by $59 \%$ of white men compared with $52 \%$ of white women $(\mathrm{p}<0.006)$ and by $60 \%$ of black men compared with $43 \%$ of black women $(p=0.004)$. Although our studies were not concurrent, they were separated by only 1-2 years and similar differences between the sexes was found by NATSSAL. ${ }^{1}$ These differences could be accounted for by a small number of women with a very large number of partners (for example, prostitutes), especially if met remote from home and beyond the reach of sexual behaviour studies.

Morbidity in relation to racial origin found in men was very similar to that reported previously in women. ${ }^{6}$ There was significantly more gonorrhoea, chlamydial infection, and nonspecific infection among black patients and a significantly higher morbidity from genital warts among our white patients. Increased morbidity from the classic bacterial STIs among black patients could not be attributed to more numerous sexual partners. However, in contrast with the increasingly prevalent viral STI, bacterial infections are all curable and our findings clearly indicate a failure in healthcare delivery to black patients.

1 Johnson AM, Wadsworth J, Wellings K, Field J. Sexual attitudes and lifestyles. Oxford: Blackwell, 1994.

2 O'Donnell L, Doval AS, Vornfett R, O'Donnell CR. STD prevention and the challenge of gender and cultural diversity: knowledge, attitudes and risk behaviours among black and hispanic inner-city STD clinic patients. Sex Transm Dis 1994;21:137-48.

3 Johnson EH, Jackson LA, Hinkle Y, et al. What is the significance of black-white differences in risky sexual behaviour? f Natl Med Assoc 1994;86:745-59.

4 Evans BA, McCormack S, Kell PD, et al. Trends in female sexual behaviour and sexually transmitted diseases in London, 1982-1992. Genitourin Med 1995;71:286-90.

5 Evans BA, Kell PD, Bond RA, MacRae KD. Heterosexual relationships and condom-use in the spread of sexually transmitted diseases to women. Genitourin Med 1995;71: 291-4.

6 Evans BA, Kell RD, Bond RA, MacRae KD. Racial origin, sexual lifestyle, and genital infection among women attending a genitourinary medicine clinic in London (1992). Sex Transm Inf 1998;74:45-9. 